\title{
Pupillary autonomic denervation with increasing duration of diabetes mellitus
}

\author{
Mark Cahill, Peter Eustace, Victor de Jesus
}

\begin{abstract}
Backgroundlaims-The autonomic pupillary changes in type I and II diabetic patients without clinical evidence of diabetic autonomic neuropathy (DAN) were compared with age matched controls. The relation between pupillary and cardiovascular autonomic function was assessed in the diabetic patients.
\end{abstract}

Methods-A case-control study was performed with diabetics grouped according to type and duration of diabetes. Static infrared pupillography was used to compare mean dark adapted pupil size and mean percentage changes in pupil size with pilocarpine $0.1 \%$ and cocaine $4 \%$ in the diabetic and control groups. All diabetic patients underwent cardiovascular autonomic function assessment using the Valsalva ratio, the $30: 15$ ratio, and testing for orthostatic hypotension.

Results-In total, 72 type I and 69 type II diabetic patients were compared with 120 controls. Mean dark adapted pupil size was significantly smaller in diabetic groups than controls. Except for type I diabetics with disease for less than 5 years, all patient groups had significantly greater mean percentage constriction in pupil size in response to dilute pilocarpine than controls. There was no significant difference between the mean percentage dilatation in response to cocaine $4 \%$ in diabetics and controls. A high proportion of patients had normal cardiovascular autonomic function particularly when this was assessed with the Valsalva ratio.

Conclusions-Denervation hypersensitivity to dilute pilocarpine is a result of damage to the pupillary parasympathetic supply of diabetic patients. This occurs before the pupillary sympathetic pathway is affected, it can be detected early in the disease, and it may be a possible explanation for the small pupil size seen in diabetic patients. Pupillary autonomic dysfunction occurs before cardiovascular autonomic changes and detection of pupil denervation hypersensitivity to dilute pilocarpine is an inexpensive way to detect early DAN.

(Br f Ophthalmol 2001;85:1225-1230)

Diabetic autonomic neuropathy (DAN) is a recognised complication of both types of diabetes mellitus, is associated with longer duration of disease, and may involve the pupil. ${ }^{1}$ One pupillary manifestation of DAN is small pupil size but the mechanism for this is unclear despite a number of previous studies that have assessed pupil function in diabetic patients using both static and kinetic methods. ${ }^{2-12}$

Pupil responses to pharmacological tests are useful in assessing parasympathetic pupil function and demonstrable pupil constriction in diabetics with dilute cholinergic agents such as metacholine or pilocarpine reflects denervation hypersensitivity secondary to post-ganglionic parasympathetic damage identical to a tonic pupil. ${ }^{13-16}$ Similarly, cocaine drops can demonstrate sympathetic pathway damage while pupil dilatation to hydroxyamphetamine or dilute phenylephrine drops differentiates between pre-ganglionic and post-ganglionic sympathetic lesions. ${ }^{13}$ Denervation hypersensitivity to dilute phenylephrine reflecting post-ganglionic sympathetic pupillary changes has also been reported in patients with DAN. ${ }^{16}$

Other manifestations of DAN include abnormal parasympathetic cardiovascular reflexes and orthostatic hypotension, a manifestation of generalised autonomic failure. ${ }^{1}$ As expected, pupillary autonomic dysfunction is demonstrable in a large proportion of patients known to have DAN..$^{2-7} 910$ However, in diabetics asymptomatic of or without DAN, the association between abnormal cardiac and pupillary autonomic reflexes is unclear with a recent report suggesting that cardiac changes are more common than pupillary. ${ }^{17}$

This study determined the progression and mechanism of pupillary changes in both types of diabetics asymptomatic of DAN, grouped according to disease duration and compared with age matched controls. Static infrared pupillography in patients and controls assessed mean dark adapted pupil size and detected pupillary parasympathetic denervation hypersensitivity by the mean percentage pupillary constriction to pilocarpine $0.1 \%$. Pupillary sympathetic function was assessed by the mean percentage pupillary dilatation to cocaine $4 \%$. The relation between pupillary and cardiovascular autonomic function was assessed in the diabetic patients.

\section{Methods}

CASES

Type I and type II diabetic patients were selected at random from the diabetic clinic of the Mater Misericordiae Hospital and asked to participate in the study. Exclusion criteria included symptoms and signs of DAN, previous laser photocoagulation therapy, previous intraocular surgery, previous intraocular inflammation, a history of tonic pupil, and current drug therapy (including treatment for glaucoma) which could interfere with autonomic nervous system function. The duration of diabetes in the patient group was calculated as that time the patient first attended the 
diabetic clinic to the time of the study rounded off to the nearest year.

CONTROLS

The controls were selected from hospital outpatients attending refraction clinics, undergoing minor surgical procedures, and attending the accident and emergency department with minor injuries. Exclusion criteria were similar to those for the patient group but also included treatment for systemic disease including diabetes mellitus, hypertension, and ischaemic heart disease. Demographic data were collected on both patient and control groups and both groups provided informed consent.

INFRARED PUPILLOGRAPHY

Infrared pupillography was performed on both patient and control groups using infrared film (Kodak infrared, 2481HS) in a $35 \mathrm{~mm}$ camera (Olympus OM2N) with a standard, camera mounted flash unit (Olympus T32) on which was attached an infrared filter (Kodak filter 88A). This was mounted on a slit lamp table with a $20 \mathrm{~mm}$ rule attached to the head rest. All pupillography was performed after a period of dark adaptation (15 minutes of fixation on a red light at 6 metres), with the pupil size being calculated from the resultant pupillographs using the incorporated $20 \mathrm{~mm}$ rule. The first set of pupillographs before any pharmacological testing corresponding to dark adapted pupil size. Subsequently the parasympathetic enervation was tested using two drops of $0.1 \%$ pilocarpine instilled into the lower conjunctival sac and repeated 3 minutes later. After an interval of 30 minutes a second set of pupillographs was taken. At least 24 hours later, following an identical period of dark adaptation the sympathetic enervation was tested by instilling two drops of cocaine $4 \%$ into the lower conjunctival sac which was repeated after 3 minutes. A third set of pupillographs was taken after 30 minutes had elapsed.

STANDARDISATION OF PUPILLARY MEASUREMENTS Pupil size was calculated from the pupillographs as the average of its vertical and horizontal diameters. The pupil size depended on the distance between the camera and the subject, the nearer the camera to the subject, the larger the photographic image, and apparent size of the pupil. A correction factor was calculated for each pupillograph by comparing the apparent length of $10 \mathrm{~mm}$ in the photograph with $10 \mathrm{~mm}$ on a ruler. If they were the same the correction factor was 1 (no correction needed), if $10 \mathrm{~mm}$ in the photograph was twice as long as on the ruler the correction factor was 2. The true size of the pupil was derived from the formula: $d=y / x$, where $d$ was the true pupillary diameter, $y$ the pupillograph diameter, and $\mathrm{x}$ the correction factor. Dark adapted pupillographs provided data for dark adapted pupil size and provided the baseline for the subsequent changes in pupil size with testing. Taking each individual baseline pupil size as $100 \%$, if pupil size halved with pilocarpine, the percentage pupillary constriction was recorded as $50 \%$, if it doubled with cocaine the percentage pupillary dilatation was $100 \%$.
ASSESSMENT OF CARDIOVASCULAR AUTONOMIC FUNCTION

Cardiovascular autonomic function was tested in the diabetic patients only using three methods previously described including the heart rate response during continuous ECG recording to the Valsalva manoeuvre where the ratio of the longest R-R interval after the manoeuvre to the shortest $\mathrm{R}-\mathrm{R}$ interval during the manoeuvre defines the Valsalva ratio (VR).$^{18}$ Similarly, the ratio of the R-R interval at beats 15 and 30 upon standing up after 3 minutes supine defined the $30: 15$ ratio. ${ }^{19} \mathrm{~A}$ VR value of 1.21 or greater was normal and less than 1.11 abnormal. A 30:15 value greater than 1.03 was normal, a value between 1.01 and 1.03 was borderline, and less than 1.00 abnormal. Thirdly, orthostatic hypotension was diagnosed if a blood pressure fall of $30 \mathrm{~mm} \mathrm{Hg}$ or more was detected by brachial artery sphygmomanometry on standing. ${ }^{20}$

\section{STATISTICAL ANALYSIS}

Univariate analysis was carried out to determine the significance of associations between the controls and each of the four groups of patients with regard to the previously outlined parameters using the Student's $t$ test for normally distributed continuous variables, the Mann-Whitney U test for continuous variables with a skewed distribution, and the $\chi^{2}$ test for categorical variables.

\section{Results}

In total, 120 hospital based controls were selected, consisting of 60 males and 60 females who were subdivided according to age into six groups of 20 patients each (males $n=10 ; 50 \%$ ) with individuals aged 5-14 years in group 1 , 15-34 years in group 2, 35-49 years in group $3,50-59$ years in group 4, 60-69 years in group 5 , and over 70 years in group 6 . In the diabetic cohort there were 72 patients with type I diabetes (males $\mathrm{n}=45 ; 62.5 \%$ ) and 69 (males $\mathrm{n}$

Table 1 Pupillary autonomic denervation with increasing duration of diabetes mellitus. Outline of disease and control comparison groups

\begin{tabular}{|c|c|c|c|c|}
\hline \multirow[b]{2}{*}{ Comparison groups } & \multirow[b]{2}{*}{ No } & \multicolumn{2}{|c|}{ Age (years) } & \multirow[b]{2}{*}{$p$ Value } \\
\hline & & Median & Range & \\
\hline \multicolumn{5}{|l|}{ IDDM: } \\
\hline $\begin{array}{l}\text { Disease }<5 \text { years' duration } \\
v\end{array}$ & 18 & 23 & $4-27$ & 0.16 \\
\hline Control groups 1-3 & 60 & 22 & $5-45$ & \\
\hline $\begin{array}{l}\text { Disease }<10 \text { years' duration } \\
v\end{array}$ & 12 & 24 & $12-32$ & 0.44 \\
\hline Control groups $1-3$ & 60 & 22 & $5-45$ & \\
\hline $\begin{array}{l}\text { Disease }<15 \text { years' duration } \\
v\end{array}$ & 10 & 35 & $20-42$ & 0.16 \\
\hline Control groups 2 and 3 & 40 & 35 & $18-45$ & \\
\hline $\begin{array}{l}\text { Disease }<20 \text { years' duration } \\
v\end{array}$ & 11 & 33 & $20-42$ & 0.23 \\
\hline Control groups 2 and 3 & 40 & 35 & $18-45$ & \\
\hline $\begin{array}{l}\text { Disease }>20 \text { years' duration } \\
v\end{array}$ & 21 & 50 & $27-67$ & 0.41 \\
\hline Control groups 2-5 & 80 & 50 & $18-69$ & \\
\hline \multicolumn{5}{|l|}{ NIDDM: } \\
\hline $\begin{array}{l}\text { Disease }<5 \text { years' duration } \\
v\end{array}$ & 34 & 58 & $33-79$ & 0.14 \\
\hline Control groups 3-6 & 80 & 60 & $35-87$ & \\
\hline $\begin{array}{l}\text { Disease }<10 \text { years' duration } \\
v\end{array}$ & 16 & 52 & $42-78$ & 0.41 \\
\hline Control groups 3-6 & 80 & 60 & $35-87$ & \\
\hline $\begin{array}{l}\text { Disease }>10 \text { years' duration } \\
v\end{array}$ & 19 & 63 & $53-73$ & 0.14 \\
\hline Control groups 4-6 & 60 & 66 & $50-87$ & \\
\hline
\end{tabular}


Table 2 Pupillary autonomic denervation with increasing duration of diabetes mellitus. Summary of pupillary measurements, disease and controls groups

\begin{tabular}{|c|c|c|c|c|c|c|c|c|c|}
\hline & \multicolumn{2}{|c|}{$\begin{array}{l}\text { Dark adapted pupil } \\
\text { size }(\mathrm{mm})\end{array}$} & \multirow[b]{2}{*}{$p$ Value } & \multicolumn{2}{|c|}{$\begin{array}{l}\% \text { Pupil constriction } \\
\text { with pilocarpine } 0.1 \%\end{array}$} & \multirow[b]{2}{*}{$p$ Value } & \multicolumn{2}{|c|}{$\begin{array}{l}\% \text { Pupil dilatation } \\
\text { with cocaine } 4 \%\end{array}$} & \multirow[b]{2}{*}{$p$ Value } \\
\hline & Mean & Range & & Mean & Range & & Mean & Range & \\
\hline \multicolumn{10}{|l|}{ IDDM: } \\
\hline$<5$ years' duration & 6.30 & $5.14-7.42$ & & 0.4 & $0-7.0$ & & 18.0 & $6.0-39.0$ & \\
\hline Groups 1-3 & 6.70 & $3.33-8.66$ & 0.014 & 0.4 & $0-13.0$ & 0.454 & 16.8 & $6.0-60.0$ & 0.318 \\
\hline$<10$ years' duration & 5.76 & $3.56-6.85$ & & 13.6 & $0-50.0$ & & 15.3 & $3.0-60.0$ & \\
\hline Groups $1-3$ & 6.70 & $3.33-8.66$ & 0.0001 & 0.6 & $0-13.0$ & $<0.0001$ & 16.3 & $6.0-60.0$ & 0.248 \\
\hline$<15$ years' duration & 6.00 & $3.33-8.33$ & & 10.5 & $0-29.0$ & & 12.6 & $1.0-25.0$ & \\
\hline Groups 2 and 3 & 6.58 & $3.33-8.33$ & 0.004 & 0.1 & $0-13.0$ & $<0.0001$ & 17.6 & $6.0-60.0$ & 0.014 \\
\hline$<20$ years' duration & 5.31 & $4.00-7.14$ & & 12.9 & $0-29.0$ & & 17.9 & $0.0-58.0$ & \\
\hline Groups 2 and 3 & 6.58 & $3.33-8.33$ & $<0.0001$ & 0.1 & $0-13.0$ & $<0.0001$ & 17.6 & $6.0-60.0$ & 0.406 \\
\hline$>20$ years' duration & 4.50 & $2.00-7.20$ & & 16.6 & $0-48.0$ & & 19.6 & $0.0-56.0$ & \\
\hline Groups 2-5 & 5.82 & $2.75-8.60$ & $<0.0001$ & 5.0 & $0-50.0$ & $<0.0001$ & 21.3 & $3.0-80.0$ & 0.286 \\
\hline \multicolumn{10}{|l|}{ NIDDM: } \\
\hline$<5$ years' duration & 4.86 & $3.12-6.28$ & & 19.7 & $0-55.0$ & & 22.6 & $1.0-54.0$ & \\
\hline Groups 3-6 & 5.24 & $2.70-8.60$ & 0.007 & 7.4 & $0-50.0$ & $<0.0001$ & 25.1 & $3.0-80.0$ & 0.200 \\
\hline$<10$ years' duration & 4.74 & $2.27-6.57$ & & 16.1 & $0-56.0$ & & 26.3 & $4.0-100.0$ & \\
\hline Groups 3-6 & 5.24 & $2.70-8.60$ & 0.007 & 7.4 & $0-50.0$ & 0.0002 & 25.1 & $3.0-80.0$ & 0.253 \\
\hline$>10$ years' duration & 4.54 & $3.14-6.66$ & & 17.2 & $0-43.0$ & & 27.4 & $0.0-65.0$ & \\
\hline Groups 4-6 & 4.96 & $2.70-8.60$ & 0.022 & 9.4 & $0-50.0$ & 0.0004 & 26.2 & $3.0-80.0$ & 0.312 \\
\hline
\end{tabular}

$=38 ; 55 \%$ ) with type II, who were classified according to disease duration (Table 1). A variable number of control groups were amalgamated to ensure an accurate age matched comparison with any given diabetic group (Table 1).

Dark adapted pupil size, percentage of baseline size with pilocarpine $0.1 \%$, and percentage of baseline size with cocaine $4 \%$ were assessed bilaterally in all subjects. No significant difference between eyes for any of these values were seen in controls or patients and the average of both eyes in each subject was used when calculating the mean values for each group. Similarly, as there was no significant difference in mean values between male and female subjects in any given group, data from both sexes were combined within groups.
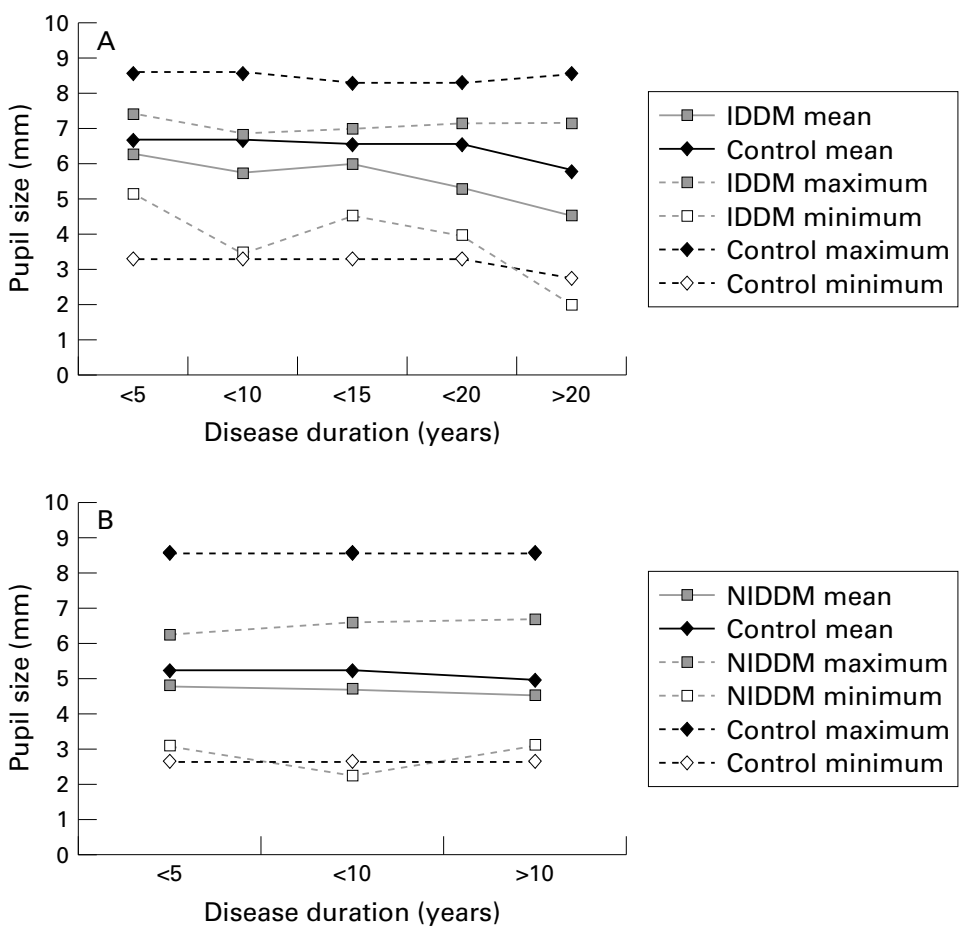

Figure 1 Pupillary autonomic denervation with increasing duration of diabetes mellitus. (A) Dark adapted pupil size, IDDM versus controls. (B) Dark adapted pupil size, NIDDM versus controls.
DARK ADAPTED PUPIL SIZE

The mean dark adapted pupil diameter decreased in size with increasing age in both the control and diabetic groups (Tables 1 and 2, Fig $1 \mathrm{~A}$ and $\mathrm{B})$. The youngest patients were those with type 1 diabetes and had a mean dark adapted pupil size of $6.30 \mathrm{~mm}$ compared with older diabetics (with type 1 or type 2 disease) where this was reduced to $4.50 \mathrm{~mm}$, a change of $1.8 \mathrm{~mm}$ (Tables 1 and 2, Fig $1 \mathrm{~A}$ and B). A similar pattern was seen in the youngest controls who had a mean dark adapted pupil size of $6.7 \mathrm{~mm}$ compared with the older controls who had a mean dark adapted pupil size of $4.96 \mathrm{~mm}$, a change of $1.74 \mathrm{~mm}$ (Tables 1 and 2, Fig $1 \mathrm{~A}$ and B). The dark adapted pupil size was significantly smaller in the diabetic groups than the controls in all comparison groups (Table 2, Fig 1A and B).

\section{PERCENTAGE PUPILLARY CONSTRICTION WITH} PILOCARPINE $0.1 \%$

There was minimal reduction in the pupil size in control groups 1-3 in response to dilute pilocarpine with a mean pupillary constriction of $1 \%$ or less. With increasing age of the control groups there was an increased response to dilute pilocarpine to a mean $9.4 \%$ change in the oldest control group (Table 2; Fig 2A and B). With the exception of the group of diabetics with type I disease for less than 5 years, all other patient groups had significantly greater mean percentage constriction in pupil size in response to dilute pilocarpine when compared with age matched controls (Table 2; Fig 2A and B).

\section{PERCENTAGE PUPILLARY DILATATION WITH} COCAINE $4 \%$

In the control groups there was a trend towards a small increase in mean percentage dilatation in response to cocaine $4 \%$ with increasing patient age (Table 2; Fig 3A and B). Overall, there was a similar trend in the diabetic groups but there was no significant difference between the mean percentage dilatation in response to cocaine $4 \%$ in diabetics when compared with age matched controls. 

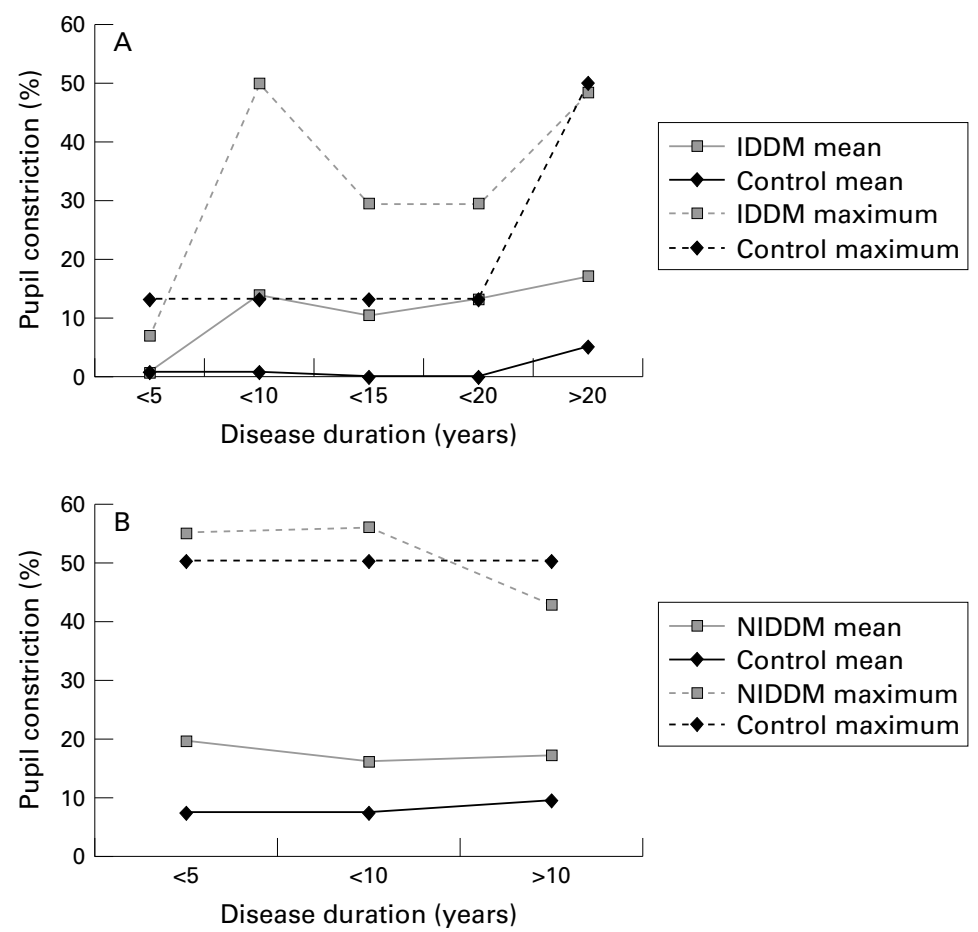

Figure 2 Pupillary autonomic denervation with increasing duration of diabetes mellitus. (A) Percentage pupillary constriction with pilocarpine $0.1 \%$, IDDM versus controls. (B) Percentage pupillary constriction with pilocarpine $0.1 \%$, NIDDM versus controls. Note: All minimum values were zero in both patients and controls in $(A)$ and $(B)$

\section{GRADE OF DIABETIC RETINOPATHY IN DIABETIC} COHORT

Overall, the majority of diabetic patients with type I disease studied had either no diabetic retinopathy or background diabetic retinopathy ( $\mathrm{n}=34,47.2 \% ; \mathrm{n}=28,39.0 \%$ respectively). A smaller proportion of type I patients had preproliferative $(\mathrm{n}=5,6.9 \%)$ or proliferative
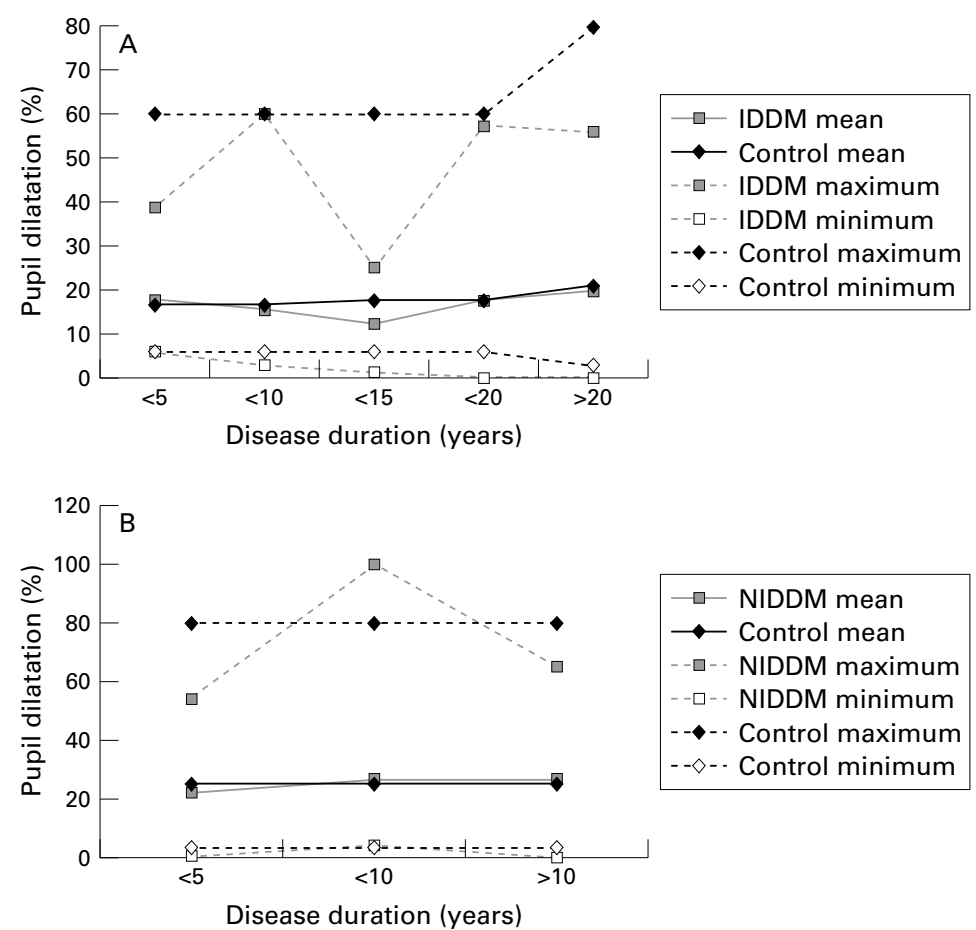

Figure 3 Pupillary autonomic denervation with increasing duration of diabetes mellitus. (A) Percentage pupillary dilatation with cocaine 4\%, IDDM versus controls. (B) Percentage pupillary dilatation with cocaine $4 \%$, NIDDM versus controls. diabetic retinopathy $(n=5,6.9 \%)$ at the time of the study. Similarly the majority of patients with type II diabetes had no diabetic retinopathy $(\mathrm{n}=41,59.4 \%)$ or background diabetic retinopathy $(\mathrm{n}=25,36.2 \%)$. A small number of type II patients had preproliferative diabetic retinopathy ( $\mathrm{n}=3,4.4 \%$ ) but no patient with type II disease had proliferative diabetic retinopathy.

ASSESSMENT OF CARDIOVASCULAR AUTONOMIC FUNCTION

All patients tested with type I diabetes of up to 20 years' duration had a normal Valsalva ratio, while only three patients $(19 \%)$ with type I diabetes for more than 20 years had an abnormal ratio. A similar trend was seen in patients with type II disease and overall the mean Valsalva ratio values for all disease groups were normal (Table 3). The proportions of patients tested with normal 30:15 ratios varied in the IDDM group but the trend in the NIDDM group was for a smaller proportion of patients with normal 30:15 ratios with increasing disease duration and patient age. As with the Valsalva ratio, the mean 30:15 ratio values in all groups were normal (Table 3). Orthostatic hypotension was detected in only one patient with type I diabetes for more than 20 years and small proportions of patients with type II disease for less than 10 years duration (Table 3).

\section{Discussion}

While a number of previous studies have demonstrated that the dark adapted pupil size in type I diabetic children and adolescents with short duration of disease but without symptoms or signs of DAN is significantly smaller than non-diabetic controls, to our knowledge this has not been demonstrated in older patients with both types of diabetes and short disease duration. ${ }^{3811}$ As in this study the majority of previous studies have demonstrated that patients with both types of diabetes with longer disease duration but no other manifestations of DAN also have smaller pupil size than controls, 2351112 although one study was inconclusive regarding the value of pupil size in these particular diabetic patients. ${ }^{9}$ As expected, studies of diabetic patients known to have DAN have demonstrated that dark adapted pupil size is reduced when compared with age matched controls. ${ }^{25}$ However, there was considerable overlap in this study of the minimum dark adapted pupil size between diabetics and controls and analysis of a larger number of patients may be required to determine definitively if diabetic pupils are smaller than those in healthy eyes.

It has been thought that failure of sympathetically mediated pupil dilatation is the mechanism for the reduced dark adapted pupil size in diabetics ${ }^{56}$ The finding in this study that the pupil response to cocaine $4 \%$ was no different in either the diabetic patients or controls demonstrates that in all likelihood the sympathetic pathway was intact in both groups. This is in contrast with a previous report, which suggested that changes in the 
Table 3 Pupillary autonomic denervation with increasing duration of diabetes mellitus. Summary of cardiovascular autonomic function data

\begin{tabular}{|c|c|c|c|c|c|c|c|c|}
\hline \multirow[b]{2}{*}{ Disease group } & \multicolumn{3}{|c|}{ Valsalva ratio } & \multicolumn{3}{|c|}{ 30:15 Ratio } & \multicolumn{2}{|c|}{$\begin{array}{l}\text { Orthostatic } \\
\text { hypotension }\end{array}$} \\
\hline & $\begin{array}{l}\text { No (\% } \\
\text { normal) }\end{array}$ & Mean & Range & $\begin{array}{l}\text { No (\% } \\
\text { normal) }\end{array}$ & Mean & Range & No & $\begin{array}{l}\% \\
\text { Present }\end{array}$ \\
\hline \multicolumn{9}{|l|}{ IDDM: } \\
\hline$<5$ years & $17(100)$ & 1.72 & $1.24-2.35$ & $17(100)$ & 1.23 & $1.03-1.60$ & 20 & 0 \\
\hline$<10$ years & $9(100)$ & 1.68 & $1.30-2.30$ & $11(72)$ & 1.24 & $1.00-1.70$ & 11 & 0 \\
\hline$<15$ years & $9(100)$ & 1.80 & $1.50-2.20$ & $10(90)$ & 1.19 & $1.00-1.70$ & 10 & 0 \\
\hline$<20$ years & $7(100)$ & 1.68 & $1.30-2.50$ & $9(100)$ & 1.17 & $1.06-1.49$ & 11 & 0 \\
\hline$>20$ years & $16(81)$ & 1.48 & $1.00-2.20$ & $19(74)$ & 1.07 & $1.00-1.40$ & 20 & 5 \\
\hline \multicolumn{9}{|l|}{ NIDDM: } \\
\hline$<5$ years & $27(96)$ & 1.54 & $1.00-2.00$ & $31(64)$ & 1.09 & $0.97-1.25$ & 34 & 3 \\
\hline$<10$ years & $12(100)$ & 1.44 & $1.20-1.80$ & $16(63)$ & 1.06 & $0.95-1.78$ & 16 & 19 \\
\hline$>10$ years & $16(81)$ & 1.29 & $1.00-1.80$ & $16(56)$ & 1.04 & $0.95-1.26$ & 16 & 0 \\
\hline
\end{tabular}

superior cervical ganglion resulting in denervation hypersensitivity of the sympathetic pathway are responsible for the pupil changes in diabetes. ${ }^{16}$ We concur with an earlier study of dark adapted pupil size and pupillary light reflex latency that pupillary sympathetic input remains normal for a prolonged, undefined period in diabetic patients. ${ }^{9}$

When tested all diabetic patients except those with type I disease for less than 5 years' duration had significantly more response to dilute pilocarpine than controls, demonstrating parasympathetic denervation of the pathway responsible for pupil constriction. To our knowledge this has been demonstrated in only one previous study of diabetic patients that used dilute metacholine to assess pupil function. ${ }^{14}$ Previous reports have stated that denervation hypersensitivity is secondary to postganglionic damage in the ciliary ganglion and other autonomic ganglia, in conditions other than diabetes. ${ }^{21-24}$ However, recent reports have demonstrated that pupillary denervation hypersensitivity can occur with pre-ganglionic and post-ganglionic lesions of the parasympathetic pathway. ${ }^{25}{ }^{26}$ Histopathological examination of the autonomic supply to the pupil could help to determine the exact location of the damage producing pupillary denervation hypersensitivity in diabetes.

Another explanation for the apparent pupillary hypersensitivity demonstrated in this paper could be increased corneal penetration of the dilute pilocarpine in diabetic eyes when compared with healthy eyes. A recent fluorophotometry study demonstrated increased penetration of fluorescein in diabetic eyes with more advanced retinopathy when compared with non-diabetic control eyes. ${ }^{27}$ In contrast, in eyes with minimal diabetic retinopathy similar to the majority of eyes in our study there was no significant difference in fluorescein corneal penetration when compared with controls. ${ }^{27}$ In another study of similar design, no difference in corneal penetration of fluorescein was demonstrated between eyes with Adie's tonic pupil and controls even though reduced corneal sensation suggestive of an altered corneal surface has been documented in a large proportion of eyes with tonic pupils. ${ }^{2428}$

A small pupil size is contrary to what would be expected with damage to the pupillary parasympathetic supply and previous authors have attributed the small pupil seen in diabetes to disruption of the pupillary sympathetic supply. ${ }^{5}$ However, as previously discussed, we have demonstrated probable preservation of the pupillary sympathetic enervation in the diabetic patients examined in this study. Interestingly, changes in pupillary parasympathetic autonomic function before sympathetic function would mirror other autonomic functions such as cardiovascular reflexes affected in DAN where parasympathetic autonomic dysfunction occurs before sympathetic. ${ }^{19}$ The presence of denervation hypersensitivity in the parasympathetic pathway could account for this finding of smaller dark adapted pupil size in diabetics even though the sympathetic system is intact, and the mechanism for this may be similar to that seen in the tonic pupil. ${ }^{29}$

The tonic pupil is a result of an acute but incomplete loss of the pupillary parasympathetic ennervation, resulting in a large pupil and other clinical features including light near dissociation. ${ }^{22}$ While neuronal misregeneration is a well known explanation for the clinical findings seen with a tonic pupil this theory does not fully explain a number of the signs including the latency of the pupil constriction, and prolonged redilatation in the dark. ${ }^{22}$ An alternative explanation is that local release of acetylcholine (ACh) from the neuromuscular junction of the ciliary muscle diffuses across the aqueous to receptor sites on denervated supersensitive iris sphincter muscle. ${ }^{29}$ An important element of this theory is the fact that the concentration of $\mathrm{ACh}$ in the aqueous is dependent on aqueous outflow and not on enzymatic hydrolysis and in light of this, the transaqueous hypothesis resolves most of the discrepancies of the neuronal misregeneration theory. ${ }^{29}$ For example, the prolonged latency of the near and light stimuli in the tonic pupil is explained by the time required for transaqueous passage of $\mathrm{ACh}$, while the prolonged latency of dark reaction is dependent on the kinetics of ACh turnover. ${ }^{29}$ Persistence of this increased cholinergic sensitivity is an accepted plausible explanation of the small pupil seen as a sequela to a tonic pupil, even in studies supporting the neuronal misregeneration theory. ${ }^{22}$ In diabetes we believe that rather than acute changes, there is a chronic, cumulative loss of the parasympathetic enervation resulting in increasing denervation hypersensitivity. This gradual loss and prolonged hypersensitivity to ACh could explain why diabetics with longer disease duration in this study, with demonstrable parasympathetic denervation, had small rather than large pupils.

This study demonstrates that while large proportions of diabetic patients from early on in the course of the disease without symptoms of DAN will have abnormal pupil parasympathetic function, only a small proportion will have abnormal cardiovascular reflexes. All tests of cardiovascular function are not the same and of those employed in this study, the Valsalva ratio which is the most reliable, was abnormal in the lowest proportion of patients. ${ }^{18-20}$ These findings confirm that pupil parasympathetic changes are seen before parasympathetic cardiovascular changes, as partially evidenced 
by two previous reports of pupil size in adolescent diabetics. ${ }^{811}$ This is in contrast with a previous report, which assessed pupil parasympathetic function using pupil constriction velocity and found the heart was denervated more often than the pupil. ${ }^{17}$

Early detection of DAN is important as it is often asymptomatic in its early stages but it is associated with a worse prognosis. ${ }^{130}$ We agree with previous reports that measurement of the pupil size is a useful indicator of autonomic function in diabetic patients but our findings demonstrate that denervation hypersensitivity of the pupil to dilute pilocarpine is also a good parameter of early autonomic dysfunction. $^{235-81112}$ Furthermore, measurement of pupil size in response to dilute pilocarpine with infrared pupillography is an inexpensive way to detect early autonomic dysfunction in all types of diabetic patients. A comparison between pupillary responses to dilute pilocarpine and kinetic pupillary tests in diabetic autonomic neuropathy may be warranted.

\section{Conclusions}

Denervation hypersensitivity to dilute pilocarpine is a result of damage to the pupillary parasympathetic supply of diabetic patients. This occurs before the pupillary sympathetic pathway is affected, it can be detected early in the disease, and it may be a possible explanation for the small pupil size seen in diabetic patients. Pupillary autonomic dysfunction occurs before cardiovascular autonomic changes and detection of pupil denervation hypersensitivity to dilute pilocarpine is an inexpensive way to detect early DAN.

1 Low PA. Diabetic autonomic neuropathy. Sem Neurol 1996;16:143-51.

Smith SE, Smith SA, Brown PM, et al. Pupillary signs in diabetic autonomic neuropathy. BMF 1978;2:924-7.

3 Hreidarsson AB. Pupil size in insulin-dependent diabetes. Rreidarsson AB. Pupil size in insulin-dependent diabetes. Relationship to duration, metabolic con

4 Pfeifer MA, Cook D, Brodsky J, et al. Quantitative evaluation of sympathetic and parasympathetic control of iris function. Diabetes Care 1982;5:518-28.

5 Smith SE, Smith SA. Reduced pupillary light reflexes in diabetic autonomic neuropathy. Diabetologia 1983;24:3302 .

6 Smith SA, Dewhirst RR. A simple diagnostic test for pupillary abnormality in diabetic autonomic neuropathy. Diabet Med 1986;3:38-41.

7 Lanting P, Heimans JJ, Reulen JP, et al. Pupillary light reflex and quantitative sensory and motor neural function tests in diabetic patients. 7 Neurol 1988;235:245-7.
8 Clarke CF, Piesowicz AT, Spathis GS. Pupillary size in children and adolescents with type 1 diabetes. Diabet Med 1989;6:780-3.

9 Lanting P, Bos JE, Aartsen J, et al. Assessment of pupillary light reflex latency and dark adapted pupil size in control subjects and in diabetic patients with and without cardiovascular autonomic neuropathy. $\mathcal{f}$ Neurol Neurosurg Psychiatry 1990;53:912-4.

10 Straub RH, Jeron A, Kerp L. The pupillary light reflex. 2 . Prevalence of pupillary autonomic neuropathy in diabetics using age-dependent age independent pupillary parameters. Ophthalmologica 1992;204:143-8.

11 Schwingshandl J, Simpson JM, Donaghue K, et al. Pupillary abnormalities in type I diabetes occurring during adolescence. Comparisons with cardiovascular reflexes. Diabetes Care 1993;16:630-3.

12 Straub RH, Thies U, Jeron A, et al. Valid parameters for investigation of the pupillary light reflex in normal and diabetic subjects shown by factor analysis and partial correlation. Diabetologia 1994;37:414-9.

13 Kardon RH, Thompson HS. The pupil. In: Rosen ES, Thompson HS, Cumming WJ, Eustace P, eds. Neuroophthalmology. 1st ed. London: Mosby, 1998:13.1-13.19.

14 Sigsbee B, Torkelson R, Kadis G, et al. Parasympathetic denervation of the iris in diabetes mellitus. $\mathcal{F}$ Neurol Neurosurg Psychiatry 1974;37:1031-5.

15 Sharma S, Hoskin-Mott A, Benstead T, et al. Correlation of the pilo-pupil average, a new test for autonomic denervation, to the severity of diabetic retinopathy. Can 7 Ophthalmol 1997;32:170-4.

16 Smith SA, Smith SE. Evidence for a neuropathic aetiology in the small pupil of diabetes mellitus. $\mathrm{Br} \mathcal{F}$ Ophthalmol 1983;67:89-93.

17 Barron SA, Rogovski Z, Kanter Y, et al. autonomic neuropathy in diabetes mellitus: the heart is denervated more often than the pupil. Electromyogr Clin Neurophysiol 1994;34:467-9.

18 Ewing DJ, Campbell IW, Burt AA, et al. Vascular reflexes in diabetic autonomic neuropathy. Lancet 1973;2:1354-6.

19 Ewing DJ, Campbell IW, Murray A, et al. Immediate heartrate response to standing: a simple test for autonomic neuropathy. BMF 1978;1:145-7.

20 Fealey RD, Robertson D. Management of orthostatic hypotension. In: Low PA ed. Clinical autonomic disorders: evaluation and management. 1st ed. Boston: Little, Brown, 1993:731-46.

21 Cannon WB. A law of denervation. Am f Med Sci 1939;198: 737.

22 Loewenfeld IE, Thompson HS. The tonic pupil: a re-evaluation. Am f Ophthalmol 1967;63:46-87.

23 Bourgon P, Pilley SF, Thompson HS. Cholinergic supersensitivity of the iris sphincter in Adie's tonic pupil. Am f Ophthalmol 1978;85:373-7.

24 Utsumi T. Corneal permeability in patients with tonic pupil. A re-evaluation of its cholinergic supersensitivity. $\mathcal{F}$ Clin Neuroophthalmol 1990;10:52-5.

25 Jacobson DM. Pupillary responses to dilute pilocarpine in preganglionic 3rd nerve disorders. Neurology 1990;40:8048.

26 Jacobson DM, Vierkant RA. Comparison of cholinergic supersensitivity in third nerve palsy and Adie's syndrome. $\mathcal{F}$ Neuroophthalmol 1998;18:171-5.

27 Sugiyama T, Utsumi T, Miyashita Y, et al. A re-evaluation of pupillary sensitivity to autonomics in diabetic patients. Nippon Ganka Gakkai Zasshi 1990;94:413-7.

28 Purcell JJ, Krachmer JH, Thompson HS. Corneal sensation in Adie's syndrome. Am f Ophthalmol 1977;84:496-500.

29 Wirtschafter JD, Volk CR, Sawchuk RJ. Transaqueous diffusion of acetylcholine to denervated iris sphincter muscle: a mechanism for the tonic pupil syndrome (Adie syndrome). Ann Neurol 1978;4:1-5

30 Ewing DJ, Campbell IW, Clarke BF. Assessment of cardiovascular effects in diabetic autonomic neuropathy and prognostic implications. Ann Intern Med 1982;92:308-11. 